\title{
Double-blind comparison of efficacy and gastroduodenal safety of diclofenac/misoprostol, piroxicam, and naproxen in the treatment of osteoarthritis
}

\author{
J A Melo Gomes, S H Roth, J Zeeh, G A W Bruyn, E M Woods, G S Geis
}

\begin{abstract}
Objectives-To compare the efficacy and gastroduodenal safety of a fixed-dose combination of diclofenac sodium $50 \mathrm{mg}$ and misoprostol $200 \mu \mathrm{g}$ twice daily with those of piroxicam $10 \mathrm{mg}$ twice daily and naproxen $375 \mathrm{mg}$ twice daily in patients with osteoarthritis.

Methods-A 4 week, randomised, doubleblind, parallel-group, multicentre study was conducted in 643 patients with symptomatic osteoarthritis of the hip and/ or knee, who required continuous nonsteroidal anti-inflammatory drug therapy for 4 weeks and who were without significant upper gastrointestinal damage as confirmed by endoscopy.

Results-For patients who had pre- and post-treatment endoscopic examinations, gastroduodenal ulcers developed in 3 $(1.5 \%)$ of 200 patients treated with diclofenac/misoprostol, $21(10 \cdot 3 \%)$ of 204 piroxicam-treated patients, and $17(8.6 \%)$ of 198 patients receiving naproxen (Chi square $=13.771, p=0.001$ ). The improvement in the osteoarthritis severity index was greater in the diclofenac/misoprostol group than in the piroxicam group $(p=0.004)$. Changes in physician and patient global assessments showed no significant differences between treatment groups. The incidences of diarrhoea and abdominal pain were higher in the diclofenac/misoprostol group than in the piroxicam and naproxen groups.

Conclusions-Diclofenac/misoprostol at twice daily dosing is associated with significantly fewer gastroduodenal ulcers than either piroxicam or naproxen. The efficacy of diclofenac/misoprostol in treating the signs and symptoms of osteoarthritis is at least comparable to that of piroxicam and naproxen.
\end{abstract}

Searle,

Box 5110,

Chicago,

III 60680-5110,

USA

J A Melo Gomes

$S$ H Roth

J Zeeh

G A W Bruyn

E M Woods

G S Geis

Correspondence to:

Dr G S Geis

Accepted for publication

22 July 1993

\section{(Ann Rheum Dis 1993; 52: 881-885)}

Nonsteroidal anti-inflammatory drugs (NSAIDs) have become the mainstay of treatment for the signs and symptoms of osteoarthritis. In the United Kingdom, NSAIDs are the most commonly prescribed treatment for osteoarthritis, accounting for over 1 million prescriptions annually. ${ }^{1}$ While patients with moderate to severe disease often require chronic dosing for adequate relief of osteoarthritis pain and inflammation, many patients with osteoarthritis can be managed with short term intermittent therapy with nonsteroidal antiinflammatory agents. Although effective in reducing symptoms and for improving the quality of life in patients with osteoarthritis, NSAIDs are not without associated side effects. The short term, intermittent dosing strategy used with these drugs has raised questions about the level of gastroduodenal damage and other side effects associated with 4 week dosing.

The magnitude of the problem of NSAIDinduced side effects is illustrated by the fact that $25 \%$ of all reported adverse drug reactions in the United Kingdom are due to nonsteroidal antiinflammatory agents, although these drugs comprise only $5 \%$ of all drugs prescribed. ${ }^{2}$ The primary safety concern with NSAIDs is the increase in serious gastrointestinal damage, including ulceration, haemorrhage, and perforation. $^{2-6}$ The therapeutic effects and many of the adverse side effects associated with NSAIDs stem from their ability to inhibit prostaglandin synthesis from arachidonic acid via the enzyme cyclooxygenase. ${ }^{7}$ In the stomach and duodenum, nonsteroidal anti-inflammatory drugs inhibit endogenous prostaglandins that play a role in maintaining mucosal defence mechanisms. $^{89}$ Various studies have indicated that as many as $30 \%$ of patients taking NSAIDs develop gastroduodenal ulcers. ${ }^{10-13}$ Furthermore, gastric ulcers have been shown to develop during short NSAID dosing-periods in osteoarthritis patients. ${ }^{14}$ However, since NSAIDinduced gastrointestinal damage is often asymptomatic, ${ }^{5} 6^{15-17}$ life-threatening complications may be the first sign that alerts the clinician to the problem. ${ }^{5}$

Misoprostol, a synthetic prostaglandin $E_{1}$ analogue, has been shown in controlled studies to prevent the development of NSAID-induced gastric and duodenal ulcers for periods of up to 1 year. ${ }^{14}{ }^{18-20}$ Relative to other anti-ulcer agents, misoprostol has been found to be significantly more effective than ranitidine or sucralfate in the prevention of NSAID-induced gastric ulcers and comparable to ranitidine in preventing these ulcers in the duodenum. ${ }^{21} 22$

NSAID-induced gastroduodenal damage in patients with arthritis may necessitate the withdrawal of the drug. A single medication that combines an NSAID with the proven gastroduodenal protectant misoprostol should allow the continuation of effecive relief of pain and 
inflammation but with a lower incidence of gastroduodenal damage.

Recent controlled studies have demonstrated that the fixed-dose combination of diclofenac and misoprostol has comparable efficacy to diclofenac in patients with rheumatoid arthritis and osteoarthritis, while being associated with significantly less gastroduodenal ulceration than diclofenac. ${ }^{23} 24$ The present study compared the efficacy and gastroduodenal safety of diclofenac sodium $50 \mathrm{mg} / \mathrm{misoprostol} 200 \mu \mathrm{g}$ twice daily, piroxicam $10 \mathrm{mg}$ twice daily, and naproxen 375 mg twice daily for 4 weeks in patients with osteoarthritis.

\section{Patients/methods}

The study was conducted between 14 June 1991 and 10 April 1992 by 51 clinical investigators from 13 countries. Patients were eligible for the study if they were: of the legal age of consent; had documented radiographic evidence (joint space narrowing, subchondral bony sclerosis; bone cysts, or gross deformity and subluxation and/or loose bodies) and symptomatic evidence of osteoarthritis of the hip and/or knee of at least 3 months' duration; had a Functional Capacity Classification of I, II, or III; ${ }^{25}$ had physician and patient global assessments of arthritis ( $1=$ very good, 2 = good, $3=$ fair, $4=$ poor, $5=$ very poor) that were rated no better than 'fair'; were experiencing joint pain, and required continuous nonsteroidal anti-inflammatory drug therapy for the duration of the study. Among the exclusion criteria were: any acute joint trauma at the site of osteoarthritis; chronic or acute renal or hepatic disorders; significant upper gastrointestinal mucosal damage $(>10$ erosions in the stomach; $>10$ erosions in the duodenum; or oesophageal, gastric, pyloric channel, or duodenal ulcer); any active gastrointestinal disease; use of any NSAID during the 10 days or any analgesic (other than paracetamol) during the 2 days before the initial (baseline) arthritis assessments; or known hypersensitivity to any nonsteroidal anti-inflammatory drug or any prostaglandin.

\section{Ethics and study design}

The study was designed as a randomised, double-blind, parallel-group multicentre trial lasting 4 weeks. Patients were randomised to receive diclofenac sodium $50 \mathrm{mg} /$ misoprostol $200 \mu \mathrm{g}$, piroxicam $10 \mathrm{mg}$, or naproxen $375 \mathrm{mg}$ twice daily for 4 weeks.

All investigational drug supplies were provided by Searle (Skokie, Illinois, USA, or local Searle facility) and consisted of: plain white tablets containing diclofenac sodium $50 \mathrm{mg}$ in a fixed combination with misoprostol $200 \mu \mathrm{g}$; plain white tablets containing placebo, identical in appearance to the fixed-combination tablets; unmarked gelatin capsules containing piroxicam $10 \mathrm{mg}$; unmarked gelatin capsules containing naproxen $375 \mathrm{mg}$; and unmarked gelatin capsules containing placebo, identical in appearance to both the piroxicam and naproxen capsules. To maintain 'blinding', all patients took one tablet and one capsule with the morning meal and one tablet and one capsule with the evening meal.

\section{Compliance and patient evaluations}

Compliance was assessed by counting the number of tablets and the number of capsules returned at week 2 and week 4 . Patients were also asked whether tablets and/or capsules were missed on more than two consecutive days.

During a pretreatment period (the 7 days immediately before the first dose of study medication), each patient provided a medical history, and physical and endoscopic examinations were performed. A blood sample was also taken from each patient and the following laboratory measurements were made: white blood cell count, haematocrit, haemoglobin, platelet count, creatinine, total bilirubin, alkaline phosphatase, aspartate aminotransferase, and alanine aminotransferase. In female patients of childbearing potential, a pregnancy test also was performed and confirmed as negative.

The endoscopy included examinations of the mucosa of the oesophagus, stomach, pyloric channel, and duodenum. The number of petechiae and erosions and the size of any ulcers were recorded. An erosion was defined as a lesion producing a definite break in the mucosa but without depth, and an ulcer was defined as a lesion with unequivocal depth.

The medical history included an estimate of the duration of osteoarthritis and various assessments of the current status of the disease including: (1) osteoarthritis severity index; ${ }^{26}(2)$ physician global assessment of arthritic condition; ${ }^{27}$ and (3) patient global assessment of arthritic condition. ${ }^{28}$ The osteoarthritis severity index was based on patient responses to questions related to osteoarthritic pain, walking distance, and activities of daily living. The maximum possible index was 24 . The physician and patient global assessments were both graded on a 5-point scale, where $1=$ very good, $2=$ good, $3=$ fair, $4=$ poor, and $5=$ very poor For the patient global assessment, the patient was asked to respond to the question: Considering all the ways your arthritis affects you, how are you doing today?

The treatment period was 4 weeks. The physical examination, clinical laboratory measurements, arthritis assessments, and endoscopic examination were repeated at the week 4 visit. In addition, any patient symptom was graded by the investigator as mild (causing no limitation of usual activities), moderate (causing some limitation of usual activities), or severe (causing inability to carry out usual activities).

\section{Statistics}

Chi square or Kruskal-Wallis nonparametric analyses were performed to determine whether patient randomisation had resulted in treatmen groups that were comparable with respect to age, sex, height, weight, race, vital signs, baseline endoscopy scores, duration of osteoarthritis, and osteoarthritis assessments on admission.

All randomised patients were included in the analyses provided they had taken at least one 
dose of study medication (intention-to-treat cohort). The main end points were the proportion of patients with and without gastroduodenal, gastric, and duodenal ulceration and the number and porportion of patients whose assessments of osteoarthritis status were much improved (that is, decreased by at least two grades from baseline), improved (that is, decreased by 1 grade from baseline), much worse (that is, increased by at least 2 grades from baseline), worse (that is, increased by 1 grade from baseline), or unchanged at week 4 . Chi square tests were used in the analysis of treatment group comparisons for all of these main end points, with the exception of the mean osteoarthritis severity index. Differences from baseline in the mean osteoarthritis index between treatment groups were compared using the Kruskal-Wallis test. Chi square analyses were performed on ulceration rates among patients who were less than 60 years of age versus those greater than or equal to 60 years of age.

All statistical testing was done using two-sided tests of significance at the $5 \%$ level.

Adverse event data were descriptively analysed. Shifts in laboratory test values also were compared within treatment groups using paired $t$ tests and across treatment groups using chi square tests.

\section{Results}

A total of 643 patients were enrolled in the study. Of these, 216 were randomised to receive diclofenac sodium $50 \mathrm{mg} / \mathrm{misoprostol} 200 \mu \mathrm{g}$ twice daily, 217 to receive piroxicam $10 \mathrm{mg}$ twice daily, and 210 to receive naproxen $375 \mathrm{mg}$ twice daily (intention to treat cohort). Table I shows that the three treatment groups were comparable with respect to age, sex, race, height, weight, and disease duration. Vital signs on admission, gastric and duodenal endoscopy scores, physician and patient global assessments of arthritic condition, functional capacity classification, and patient assessment of joint pain also were comparable among the treatment groups. A statistically significant treatment group difference was noted in the baseline osteoarthritis severity index $(p=0 \cdot 024)$.

Table 1 Baseline characteristics of intention-to-treat cohort. Data expressed as numbers (percentages) of patients

\begin{tabular}{lcccc}
\hline & $\begin{array}{c}\text { Diclofenac/misoprostol } \\
(n=216)\end{array}$ & $\begin{array}{c}\text { Piroxicam } \\
(n=217)\end{array}$ & $\begin{array}{c}\text { Naproxen } \\
(n=210)\end{array}$ & $p$ Value \\
\hline $\begin{array}{l}\text { Age (years) } \\
\text { Mean }\end{array}$ & & & & $0 \cdot 117$ \\
$\quad$ Range & $60 \cdot 7$ & $58 \cdot 7$ & $59 \cdot 5$ & \\
Sex & $30-84$ & $26-89$ & $33-85$ & $0 \cdot 835$ \\
$\quad$ Male & $52(24)$ & $55(25)$ & $48(23)$ & \\
$\quad$ Female & $164(76)$ & $162(75)$ & $162(77)$ & $0 \cdot 982$ \\
Race & & & & \\
White & $177(82)$ & $172(79)$ & $169(80)$ & \\
Black & $17(8)$ & $21(10)$ & $20(10)$ & \\
Other & $22(10)$ & $24(11)$ & $21(10)$ & $0 \cdot 638$ \\
Height, mean (cm) & $161 \cdot 4$ & $161 \cdot 8$ & $162 \cdot 6$ & $0 \cdot 863$ \\
Weight, mean (kg) & $77 \cdot 5$ & $76 \cdot 3$ & $77 \cdot 2$ & $0 \cdot 395$ \\
Disease duration (years) & & & & \\
$\quad<0 \cdot 5$ & $4(2)$ & $6(3)$ & $1(0)$ & \\
$\quad 0 \cdot 5-0 \cdot 9$ & $9(4)$ & $10(5)$ & $9(4)$ & \\
$1 \cdot 0-4 \cdot 9$ & $72(33)$ & $94(43)$ & $79(38)$ & \\
$5 \cdot 0-9 \cdot 9$ & $69(32)$ & $44(20)$ & $59(28)$ & \\
$10 \cdot 0-14 \cdot 9$ & $39(18)$ & $30(14)$ & $30(14)$ & \\
$\geq 15 \cdot 0$ & $23(11)$ & $32(15)$ & \\
\hline
\end{tabular}

Of the 643 patients enrolled, 578 completed the study (193, diclofenac/misoprostol; 200, piroxicam; and 185, naproxen). The primary reasons for withdrawal were adverse events $(48$ patients) and protocol violations (12 patients). The number of patients withdrawn were similar in the three treatment groups.

Forty one patients did not have a final (week 4) endoscopy performed (16 patients, diclofenac/misoprostol; 13 patients, piroxicam; and 12 patients, naproxen). These patients with unknown outcomes were not included in the endoscopic analyses presented below, since in analyses that included patients with unknown outcomes, the statistical conclusions were comparable.

Statistically significant differences were found in the proportion of patients with gastroduodenal, gastric, and duodenal ulcer in the three treatment groups at week 4 endoscopy (table 2). For patients with gastroduodenal ulcer, pairwise comparisons between treatment groups demonstrated statistically significant differences between diclofenac/misoprostol and piroxicam $(p<0.001)$ and between diclofenacl misoprostol and naproxen $(p=0.001)$. No significant difference was found between the piroxicam and naproxen groups $(p=0.56)$. For patients with gastric ulcer, pairwise comparisons between treatment groups demonstrated statistically significant differences between diclofenac/misoprostol and piroxicam ( $p=0.007$, between diclofenac/misoprostol and naproxen $(p=0.004)$, but not between piroxicam and naproxen $(p=0.78)$. For patients with duodenal ulcer, pairwise comparisons between treatment groups demonstrated a statistically significant difference only between diclofenac/misoprostol and piroxicam $(p=0.002)$.

In all three treatment groups, chi square analyses of gastroduodenal ulceration rates among patients less than 60 years of age versus those greater than or equal to 60 years demonstrated no statistical significance ( $p$ values $>0 \cdot 11$ ).

In the intention-to-treat cohort, an overall analysis of the change from baseline in the osteoarthritis severity index at week 4 of treatment indicated a statistically significant treatment difference (table 3; $\mathrm{p}=0.015$ ). Pairwise comparisons between treatments only demonstrated statistical significance in favour of diclofenac/misoprostol versus piroxicam $(p=0.004)$. No treatment differences were found in analyses of change from baseline in the physician's global assessment or patient's global assessment of arthritic condition (table 3).

The mean compliance with study medication at the final visit was at least $95 \%$ for each of the three treatment groups. No significant differences between treatment groups were demonstrated.

A total of 120 different adverse events were reported by 438 of the $643(68 \cdot 1 \%)$ patients enrolled in this 4-week study. Adverse events were reported by $130(60 \cdot 2 \%)$ of patients treated with diclofenac/misoprostol, by 151 $(69.6 \%)$ of those treated with piroxicam, and by 
$157(74 \cdot 8 \%)$ of those receiving naproxen. Adverse events affecting the gastrointestinal system were most common for each medication. The incidences of abdominal pain and diarrhoea were higher in the diclofenac/misoprostol group than in the piroxicam or naproxen groups (table 4). However, $69 \%$ of the episodes of abdominal pain and $88 \%$ of the episodes of diarrhoea in the diclofenac/misoprostol group were mild or moderate in severity (table 5).

Five patients (1, piroxicam; 4, naproxen) withdrew from the study after 4 to 18 days of treatment due to haematemesis or melaena. In three of these five patients (1, piroxicam; 2 , naproxen), the source of the bleeding was gastroduodenal, as confirmed by endoscopy. In one of the remaining patients treated with naproxen, endoscopy revealed oesophageal erosions as the source of bleeding. This patient was admitted to hospital and required a blood transfusion. The bleeding source could not be

Table 2 Proportions of patients with gastroduodenal, gastric, and duodenal ulcer in diclofenac/misoprostol, piroxicam, and naproxen treatment groups at final (week 4) endoscopy. Data expressed as numbers (percentages) of patients

\begin{tabular}{lllll}
\hline & $\begin{array}{l}\text { Diclofenac/misoprostol } \\
(n=200)\end{array}$ & $\begin{array}{l}\text { Piroxicam } \\
(n=204)\end{array}$ & $\begin{array}{c}\text { Naproxen } \\
(n=198)\end{array}$ & $p$ Value $^{\star}$ \\
\hline Gastroduodenal ulcer & $3(1 \cdot 5)$ & $21(10 \cdot 3)$ & $17(8 \cdot 6)$ & $0 \cdot 001$ \\
Gastric ulcer & $3(1.5)$ & $14(6.9)$ & $15(7 \cdot 6)$ & $0 \cdot 012$ \\
Duodenal ulcer & $0(0)$ & $10(4 \cdot 9)$ & $3(1 \cdot 5)$ & 0.002 \\
\hline
\end{tabular}

${ }^{\star}$ Overall treatment comparison for patients with ulcer.

Table 3 Changes from baseline in osteoarthritis assessments at final (week 4) visit (intention-to-treat cohort). Data expressed as means or numbers (percentages) of patients

\begin{tabular}{lcccc}
\hline & $\begin{array}{l}\text { Diclofenac/misoprostol } \\
(n=216)\end{array}$ & $\begin{array}{c}\text { Piroxicam } \\
(n=217)\end{array}$ & $\begin{array}{c}\text { Naproxen } \\
(n=210)\end{array}$ & $p$ Value \\
\hline $\begin{array}{l}\text { Mean osteoarthritis severity } \\
\text { indext }\end{array}$ & $-4 \cdot 27$ & & & \\
Physician global assessment & $53(25)$ & $-3 \cdot 19$ & $-3 \cdot 79$ & $0 \cdot 015$ \\
$\quad$ Much improved & $102(47)$ & $45(21)$ & $44(21)$ & $0 \cdot 78$ \\
Improved & $41(19)$ & $100(46)$ & $97(46)$ & \\
Unchanged & $1(0)$ & $52(24)$ & $45(21)$ & \\
Worse & $0(0)$ & $4(2)$ & $3(1)$ & \\
Much worse & $19(9)$ & $0(0)$ & $0(0)$ & \\
Unknown & $77(36)$ & $16(7)$ & $21(10)$ & $0 \cdot 27$ \\
Patient global assessment & $87(40)$ & $67(31)$ & $59(28)$ & \\
Much improved & $30(14)$ & $79(36)$ & $79(38)$ & \\
Improved & $2(1)$ & $48(22)$ & $46(22)$ & \\
Unchanged & $1(0)$ & $7(3)$ & $5(2)$ & \\
Worse & $19(9)$ & $1(0)$ & $0(0)$ & \\
Much worse & $15(7)$ & $21(10)$ & \\
Unknown & & & \\
\hline
\end{tabular}

ॠ Overall treatment comparison.

†Based on patients with known outcomes.

Table 4 Incidences of most common gastrointestinal adverse events in intention-to-treat cohort. Data expressed as numbers (percentages) of patients

\begin{tabular}{llll}
\hline & $\begin{array}{l}\text { Diclofenac/misoprostol } \\
(n=216)\end{array}$ & $\begin{array}{l}\text { Piroxicam } \\
(n=217)\end{array}$ & $\begin{array}{l}\text { Naproxen } \\
(n=210)\end{array}$ \\
\hline Abdominal pain & $45(20 \cdot 8)$ & $34(15 \cdot 7)$ & $37(17 \cdot 6)$ \\
Diarrhoea & $39(18 \cdot 1)$ & $12(5 \cdot 5)$ & $10(4 \cdot 8)$ \\
Dyspepsia & $18(8 \cdot 3)$ & $25(11 \cdot 5)$ & $20(9 \cdot 5)$ \\
Nausea & $18(8 \cdot 3)$ & $11(5 \cdot 1)$ & $18(8 \cdot 6)$ \\
\hline
\end{tabular}

Table 5 Characteristics of selected adverse events in intention-to-treat cohort

\begin{tabular}{|c|c|c|c|c|c|c|c|c|}
\hline & \multirow{2}{*}{$\begin{array}{l}\text { Number } \\
\text { of } \\
\text { patients }\end{array}$} & \multirow{2}{*}{$\begin{array}{l}\text { Median } \\
\text { number of } \\
\text { episodes }\end{array}$} & \multirow{2}{*}{$\begin{array}{l}\text { Median days } \\
\text { to onset of } \\
\text { first episode }\end{array}$} & \multirow{2}{*}{$\begin{array}{l}\text { Median } \\
\text { duration } \\
\text { (days) }\end{array}$} & \multicolumn{3}{|c|}{ Severity of episodes } & \multirow{2}{*}{$\begin{array}{l}\text { Patients } \\
\text { withdrawn }\end{array}$} \\
\hline & & & & & Mild & Moderate & Severe & \\
\hline \multicolumn{9}{|l|}{ Abdominal pain } \\
\hline Diclofenacl & & & & & & & & \\
\hline misoprostol & 45 & $1 \cdot 0$ & $2 \cdot 5$ & $2 \cdot 0$ & 29 & 19 & 22 & 8 \\
\hline Piroxicam & 34 & $1 \cdot 0$ & $11 \cdot 5$ & $4 \cdot 0$ & 21 & 17 & 4 & 3 \\
\hline Naproxen & 37 & $1 \cdot 0$ & $8 \cdot 0$ & $4 \cdot 0$ & 16 & 19 & 10 & 9 \\
\hline \multicolumn{9}{|l|}{ Diarrhoea } \\
\hline Diclofenac/ & & & & & & & & \\
\hline misoprostol & 39 & $1 \cdot 0$ & $3 \cdot 0$ & 1.0 & 30 & 15 & 6 & 3 \\
\hline Piroxicam & 12 & 1.0 & $12 \cdot 0$ & $1 \cdot 0$ & 10 & 7 & 2 & 0 \\
\hline Naproxen & 10 & $1 \cdot 0$ & 4.5 & $1 \cdot 0$ & 9 & 2 & 4 & 3 \\
\hline
\end{tabular}

confirmed in the remaining patient treated with naproxen.

Five laboratory measurements showed statistically significant changes from baseline values within the treatment groups. When the overall distribution of shifts (increase, decrease, or no change) in laboratory measurements were compared across treatment groups by chi square tests, only the shifts in alanine aminotransferase showed significant differences $(p=0.003)$.

\section{Discussion}

This study demonstrated that the fixed combination of diclofenac and misoprostol is associated with fewer gastroduodenal ulcers than either piroxicam or naproxen. The doses of diclofenac/misoprostol and naproxen used in this study were not the highest recommended adult doses but were in the range of doses recommended for treating the signs and symptoms of osteoarthritis. The $1.5 \%$ overall incidence of gastroduodenal ulcer with diclofenac/misoprostol found in this study of osteoarthritis patients is in agreement with incidences of $0-4 \%$ reported previously in patients with rheumatoid arthritis or osteoarthritis. ${ }^{23} 24$ The gastroduodenal ulceration rates for piroxicam and naproxen demonstrated in this study, $10.3 \%$ and $8.6 \%$, respectively, indicate that these two widely prescribed nonsteroidal anti-inflammatory drugs have similar propensities for causing gastroduodenal ulcers and that a significant number of ulcers do develop during only 4 weeks of treatment.

Gastroduodenal ulcer development in this study was not dependent on the age of the patient. Younger patients ( $<60$ years) were not at a lower risk of nonsteroidal anti-inflammatory drug-induced gastroduodenal ulcer than were older patients ( $\geq 60$ years). Thus both younger and older patients treated with diclofenac/ misoprostol benefit from the mucosal protectant misoprostol.

Although not statistically significant, of clinical interest was the finding that five patients in the piroxicam or naproxen treatment groups experienced haematemesis or melaena after 4 to 18 days of treatment. These cases support the occurrence of gastrointestinal bleeding during short dosing periods with most NSAIDs.

Other confounding factors may predispose patients to NSAID gastropathy. For example, in a survey of 185 patients with RA who were receiving NSAID therapy, $63 \%$ of patients with gastric ulcer and $65 \%$ of those with duodenal ulcer were smokers. ${ }^{29}$ In contrast, only $34 \%$ of patients without ulcer were smokers. The authors concluded that smoking was associated with peptic ulcer in patients with RA. In contrast, Fries has reported that multiple regression analysis of prospective data from the Arthritis, Rheumatism and Aging Medical Information System (ARAMIS) for RA patients showed that cigarette smoking is not a risk factor for NSAID gastropathy. ${ }^{30}$ Smoking as a possible confounding factor was not evaluated in our study.

Many clinical studies have investigated the ability of various therapeutic agents to prevent 
NSAID-induced ulcers. ${ }^{14}$ 18-22 $31-35$ The results of these studies have indicated that the $\mathrm{H}_{2}$-receptor antagonist ranitidine was not effective in preventing NSAID-associated gastric ulcers but was effective in preventing duodenal ulcers. $^{31}{ }^{32}$ Sucralfate has not been shown to be effective in preventing NSAID-induced gastric or duodenal ulcers. ${ }^{22}{ }^{33}$ Although the proton pump inhibitor omeprazole protected the duodenum of healthy subjects from short-term NSAIDinduced damage, significant protection of the gastric mucosa was not demonstrated. ${ }^{35}$ In contrast, the prostaglandin analogue misoprostol has been shown to significantly reduce the incidence of both gastric and duodenal ulcers in NSAID users. ${ }^{14}$ 18-20

The adverse events found most frequently in this study were gastrointestinal in nature, that is, abdominal pain, diarrhoea, dyspepsia, and nausea. The incidences of abdominal pain and diarrhoea were higher in the diclofenac/ misoprostol group than in the piroxicam or naproxen group. In our study and as reported previously, ${ }^{2021}$ these two adverse events were usually mild or moderate in severity and occurred and resolved during the first week of therapy with diclofenac/misoprostol. Only 9 $(4 \cdot 2 \%)$ of 216 patients receiving diclofenad misoprostol withdrew from the study due to abdominal pain or diarrhoea compared with 3 $(1 \cdot 4 \%)$ piroxicam patients and $11(5 \cdot 2 \%)$ naproxen patients.

The three measures of efficacy used in this study (osteoarthritis severity index and physician and patient global assessments of arthritic condition) demonstrated that the fixed combination of diclofenac and misoprostol, at twice daily dosing, was at least comparable to piroxicam and naproxen, at the doses administered, in treating the signs and symptoms of osteoarthritis. These results support those from other studies that showed that the presence of misoprostol in the fixedcombination tablet did not interfere with the antiarthritic efficacy of diclofenac. ${ }^{23} 24$

The patients enrolled in our study are likely to be representative of the general population of patients with osteoarthritis using NSAIDs. Physicians now have a medication for treating patients, regardless of their age or sex, which is at least comparable to traditional NSAIDs for arthritis relief, but with approximately $85 \%$ fewer gastroduodenal ulcers.

1 Committee on Safety of Medicines. CME update: nonsteroidal anti-inflammatory drugs and serious nonsteroidal anti-inflammatory drugs and serious
gastrointestinal adverse reactions-2. BMf 1986; 292: gastrointest

2 Roth S H, Bennett R E. Nonsteroidal anti-inflammatory drug gastropathy. Arch Intern Med 1987; 147: 2093-2100.

3 Larkai E N, Smith J L, Lidsky M D, Graham D Y. Gastroduodenal mucosa and dyspeptic symptoms in arthritic patients during chronic nonsteroidal antiinflammatory drug use. Am $\mathcal{f}$ Gastroenterol 1987; 82: 1153-8.

4 Coles L S, Fries J F, Kraines R G, Roth S F. From experiment to experience: side effects of nonsteroidal anti-inflammatory drugs. Am Med $\mathcal{F} 1983 ; 74: 820-8$.

5 Armstrong C P, Blower A L. Nonsteroidal antiinflammatory drugs and life-threatening complications of peptic ulceration. Gut 1987; 28: 527-32.

6 Jaszewski R. Frequency of gastroduodenal lesions in asymptomatic patients on chronic aspirin or nonsteroidal antiinflammatory drug therapy. $\mathcal{F}$ Clin Gastroenterol 1990; 12: $10-13$.

7 Vane J R. Inhibition of prostaglandin synthesis as a mechanism of action for aspirin-like drugs. Nature New Biol 1971; 231: 232-5.

8 Whittle B J R, Vane J R. A biochemical basis for the gastrointestinal toxicity of non-steroid antirheumatic drugs. Arch Toxicol 1984; Supp 7: 315-22.

9 Fromm D. Mechanisms involved in gastric mucosa resistance to injury. Ann Rev Med 1987; 38: 119-128.

10 Collins A J, DuToit J A. Upper gastrointestinal findings and faecal occult blood in patients with rheumatic diseases taking nonsteroidal anti-inflammatory drugs. $\mathrm{Br} \mathcal{F}$ Rheumatol 1987; 26: 295-8.

11 Sontag S, Schnell T, Mak E, Adelman K, Miller T, Schleifer $J$, Skibbens K. NSAIDs with or without prednisone: bad news for the gut mucosa. Gastroenterology 1989; 96: news for.

12 Geis G S, Stead H, Wallenmark C-B, Nicholson P A Prevalence of mucosal lesions in the stomach and Prevalence of mucosal lesions in the stomach and
duodenum due to chronic use of NSAIDs in patients with duodenum due to chronic use of NSAIDs in patients with
rheumatoid arthritis or osteoarthritis, and interim report rheumatoid arthritis or osteoarthritis, and interim report
on prevention by misoprostol of diclofenac associated on prevention by misoprostol of diclofenac as
lesions. $\mathcal{F}$ Rheumatol 1991; 18 (suppl 28): 11-14.

13 Morgan R. Non-aspirin nonsteroidal anti-inflammatory drugs and active gastroduodenal ulceration in the elderly. Br f Rheumatol 1987; 16: 158-9.

14 Graham D Y, Agrawal N H, Roth S H. Prevention of NSAID-induced gastric ulcer with misoprostol: a multicentre, double-blind, placebo-controlled trial. Lancet 1988; ii: 1277-80.

15 Jorde R, Burhol P G. Asymptomatic peptic ulcer disease. Scand 7 Gastroenterol 1987; 22: 129-134.

16 Shallcross T M, Heatley R V. Effect of nonsteroidal antiinflammatory drugs on dyspeptic symptoms. $B M \mathcal{F} 1990$; 300: 568-9.

17 Skander M P, Ryan F P. Nonsteroidal anti-inflammatory drugs and pain-free peptic ulceration in the elderly. $B M F$ $1988 ; 297: 833-4$

18 Graham D Y, Stromatt S C, Jaszewski R, White R H, Triadafilopoulos G. Prevention of duodenal ulcer in arthritics who are chronic NSAID users: a multicenter trial of the role of misoprostol. Gastroenterology 1991; 100: A75.

19 Geis G S, Erhardt L J, Stead H. Prevention of diclofenacinduced gastroduodenal mucosal lesions by misoprostol: a multinational, placebo-controlled, parallel group study. Hung Rheumatol 1991; 32: 366.

20 Geis G S, Erhardt L J, Stead H. Prevention of diclofenacinduced gastroduodenal mucosal ulcers by misoprostol: a induced gastroduodenal mucosal ulcers by misoprostol: a

21 White R, Raskin J B, Jaszewski R, Teoh L S, Sue S O. Misoprostol and ranitidine in the prevention of NSAIDMisoprostol and ranitidine in the prevention of NSAIDinduced gastric and duodenal

22 Agrawal N M, Roth S, Graham D Y, et al. Misoprostol compared with sucralfate in the prevention of nonsteroidal anti-inflammatory drug-induced gastric ulcer. Ann Intern Med 1991; 115: 195-200.

23 Verdickt W, Moran C, Hantzschel H, Fraga A M, Stead H, Geis G S. A double-blind comparison of the gastroduodenal safety and efficacy of diclofenac and a fixed dose combination of diclofenac and misoprostol in the treatment of rheumatoid arthritis. Scand $\mathcal{F}$ Rheumatol 1992; 21: 85-91.

24 Bolton W, Melo Gomes J A, Stead H, Geis G S. The gastroduodenal safety and efficacy of the fixed combination of diclofenac and misoprostol in the treatment of osteoarthritis. Br 7 Rheumatol 1992; 31: 753-8.

25 Steinbrocker O, Traiger C H, Batterman R C. Therapeutic criteria in rheumatoid arthritis. $\mathcal{F} A M A$ 1949; 140: 659-62.

26 Lequesne M G, Mery C, Samson M, Gerard P. Indexes of severity for osteoarthritis of the hip and knee. Scand $\mathcal{F}$ Rheumatol 1987; suppl 65: 85-89.

27 Cooperating Clinics Committee of American Rheumatism Association. A seven-day variability study of 499 patients with peripheral rheumatoid arthritis. Arthritis Rheum 1965; 8: 302-34.

28 Ward J R, Williams H J, Egger M J, et al. Comparison of auranofin, gold sodium thiomalate and placebo in the treatment of rheumatoid arthritis. Arthritis Rheum 1983; 26: 1303-315.

29 Farah D, Sturrock R D, Russell R I. Peptic ulcer in rheumatoid arthritis. Ann Rheum Dis 1988; 47: 478-80.

30 Fries J F. NSAID gastropathy: Epidemiology. $\mathcal{f}$ Musculoskel Med 1991; 8: 21-28.

31 Ehsanullah R S B, Page M C, Tildesley G, Wood J R. Prevention of gastroduodenal damage induced by nonsteroidal anti-inflammatory drugs: controlled trial with ranitidine. $B M F$ 1988: 297: 1017-21.

32 Robinson M G, Griffin J W, Bowers J, et al. Effect of ranitidine on gastroduodenal mucosal damage induced by nonsteroidal anti-inflammatory drugs. Dig Dis Sci 1989; 34: 424-8.

33 Gudjonsson $\mathrm{H}$, Oddsson E, Thjodleifsson B. Protective effect of sucralfate against naproxen-induced damage to the human gastroduodenal mucosa (abst.). Scand $\mathcal{f}$ Gastroenterol 1990; 25 (suppl 176): 24

34 Stern A I, Ward F, Sievert W. Lack of gastric mucosal protection by sucralfate during long-term aspirin ingestion in humans. Am 7 Med 1989; 86 (suppl 6A): 66-69.

35 Oddsson E, Gudjonsson H, Thjodleifsson B. Protective effect of omeprazole or ranitidine against naproxen-induced damage to the human gastroduodenal mucosa (abstract). Scand $f$ Gastroenterol 1990; 25 (suppl 176): 13. 